\title{
Dietary behavior and its relation with lifestyle, rotating work shifts and job satisfaction among nurses of Ain Shams university hospitals
}

\author{
Sally Adel Hakim*, Waleed Salah Eldin*, Amira Mohsen** \\ *Department of Community Medicine, Environmental and Occupational Medicine - \\ Faculty of Medicine - Ain Shams University \\ * Department of Community Medicine, National Research Center, Cairo, Egypt
}

\begin{abstract}
:
Background: Shift work induces stress, disturbs family life and interrupts regular meal schedules. Few studies have addressed the association between shift work and abnormal eating behavior among hospital nurses. Objectives: The objective of this study was to determine the relationship between eating behavior and personal lifestyles, job satisfaction, and gastrointestinal symptoms among nurses working in night shift. Methodology: cross-sectional study with internal comparisons of a sample of 400 nurses working in rotating shift for at least one year in the Ain Shams University Hospitals. Data about socio-demographic characteristics, work conditions, dietary behavior and job satisfactions were collected using three questionnaires. Weight and height were measured for calculating body mass index. Results: Overall, the majority of nurses had semihealthy diet (89\%), $8.8 \%$ of them had Unhealthy Diet while only $2.2 \%$ ate a healthy diet. Middle Age group, smoking, longer duration of work in rotating shifts and working in surgery departments are factors associated with unhealthy diet. No significant difference was found between nurses with different dietary behaviors and job satisfaction; however those with unhealthy diet have more frequent abdominal symptoms compared to those with semi healthy or healthy diet. Conclusions and recommendation: Duration of shift work was positively associated with abnormal eating behavior among nurses working in Ain Shams university hospitals. More health promotional programs should be targeted towards hospital nurses whose duties require frequent shifts to enhance healthy eating.
\end{abstract}

\section{Introduction}

The workplace is defined as an environment in which workers and managers collaborate to promote the health and wellbeing of all workers (1). Also, the worksite is internationally recognized as an appropriate setting for health promotion and disease prevention as this is where working individuals could spend up to $60 \%$ of their waking hours ${ }^{(2-3)}$. Employees including nurses are at increased risk of NonCommunicable Diseases (NCDs) like diabetes, hypertension and coronary heart diseases (CHD) ${ }^{(4)}$. The main risks of NCDs are physical inactivity, unhealthy eating, smoking and alcohol abuse ${ }^{5}$.

Because patient care cannot be confined to usual working hours $(09 \mathrm{~h} 00-17 \mathrm{~h} 00)$, approximately a quarter of all nurses work nontraditional hours or shifts 6${ }^{7}$.Shift work can have a negative impact on the employee and could lead to 
increased drug use, job related stress, poor job performance, insomnia, and disrupted social and family life ${ }^{8}$. The high prevalence of health related conditions and risk factors such as obesity, overweight, physical inactivity, and poor eating habits have been reported amongst shift and rotational night shift workers ${ }^{\mathbf{9 - 1 0}}$.

Level of job satisfaction is an extent to which person likes or dislikes his job. Multiple factors can influence persons level of job satisfaction; this factor range from the level of pay and benefits, perceived fairness of promotion system within the organization, the quality of working conditions to leadership and social relationship ${ }^{\mathbf{1 1}}$.

According to a study, night working is considered as a kind of challenge among most nurses and can lead to several forms of physical and emotional disorders ${ }^{12}$. Shift duties were positively associated with abnormal eating habits among hospital nurses. Studies on the effects of shift work on eating habits and nutrients intake have previously been conducted on shift workers in different jobs 13. Shift workers preferred to eat cold and fast foods and tend to have a nibble rather than a meal and have fewer meals over 24 hours ${ }^{14}$. These eating habit changes may in- crease or decrease intake of nutrients. Shift work and insufficient rest, as both are considered the main obstacle to healthy eating by respondents. Obesity has been shown to be more prevalent among shift workers and is associated with higher BMI, independently of age and work duration. Several mechanisms explain weight gain in shift workers, such as higher calorie intake, changes in dietary habits such as eating fewer meals, more snacks and in the circadian distribution of food ${ }^{\mathbf{1 5}}$. Few studies adequately assess nutrient intakes and the impact of timing of intake ${ }^{\mathbf{1 6}}$. The present study aimed at studying the dietary behavior of nurses attending rotating shifts and its relation to some socio-demographic characteristics, lifestyle and work related factors. Moreover, to identify the relation between the dietary behavioral status and gastrointestinal complaint.

\section{Subjects and Methods}

Study design: This is a cross-sectional study with internal comparisons of a sample of 400 nurses working in night shift for at least one year.

Time of the study: data were collected during the period from July to October 2015.

\section{Study setting, population and sample size calculation:}

This study was conducted in the Ain Shams University Hospitals. In this study nurses working in the main hospitals (Surgery, Internal Medicine, Pediatrics and Obstetrics \& Gynecology) were included in the study. The list of all nurses working in the four hospitals was obtained from the central administration department of the hospital in order to calculate the sample size. For calculating the sample size we assumed the abnormal dietary behavioral percent among nurses of $50 \% \pm 5 \%$ and using alpha level of 0.05 and power test of $80 \%$. This assumptions yield a sample of 350 nurses. For internal analysis to identify factors associated with dietary behavioral; the sample increased to 400 nurses.

\section{Study tools:}


Three questionnaires were used: the first one was composed of sociodemographic, life style characteristics and work conditions. The second one used was for assessment of dietary behavior. The third one was applied for assessment of job satisfaction. Weight and height were measured for calculating body mass index.

\section{Dietary Behavior questionnaire:}

Type of diet intake was assessed by an interview questionnaire designed by the authors after intensive searching for different questionnaires used for assessment of diet behavior. The used questionnaire consisted of 10 questions. All questions related to the average intake per week. The answer after each question is one of the 3 options: one or rare, 2 to 3 times, 4 and more times per week. The questionnaire included questions related to eating red meat, fish and poultry, lentils\& beans, cheese \& dairy products, vegetables\& fruits, eggs, fast food, the frequency of having breakfast, frequency of removing poultry skin and their common desert. Each question was given a score from 1 to 3 and considering 3 as healthy behavior. The total score was ranged between 10 and 30 . The following classification was applied: unhealthy diet for those with score less than 15 , semi healthy diet for those with score 15 to 22 while healthy diet for those with score equal or more than 22 .

\section{Job satisfaction questionnaire:}

Job satisfaction was assessed using the Job Satisfaction Survey (JSS), with Copyright Paul E. Spector 1994, all rights reserved ${ }^{17}$. The questionnaire included items as satisfaction with: payment, promotion, supervisor, rules and procedures at work, colleagues, value of the job, being appreciated for the task you do, having a sense of pride in doing your job. The answers were on a scale from disagreeing very much to agree very much. We used the 36 item questionnaire where possible scores range from 36 to 216; 36-108: dissatisfaction, 144-216: satisfaction and 108-144: ambivalent (uncertain).

Regarding physical activity: we asked about frequency of exercise in the last 30 days: (no / rare), ( $>3$ times/week) and we asked also about the exercise intensity for those answered yes. The classification of the physical intensity as follows; light (no/slight increase in heart rate and respiration, no sweating) moderate (noticeable increase in heart rate and respiration, some sweating) heavy (fast heart rate, labored respiration, obvious sweating).

Body weight was measured in light clothing using a weighing scale and recorded to the nearest kilogram. Height was measured to the nearest centimeter on vertical scale without shoes. Body mass index (BMI) was calculated as follows: weight $(\mathrm{kg})$ / (height in meter square). BMI was categorized as follows: normal weight 18.5 to 24.9 ; over weight 25 to 29.9 ; obese $\geq 30$.

\section{Statistical Analysis:}

Data collected were entered in Microsoft Excel 2007 then transferred to SPSS format. SPSS software version 20 was used for all statistical analysis. For summarizing study qualitative variables ; frequency and percentages were done while for quantitative variables mean, median, standard deviation (SD), median and interquartile range were used. Both chi square test $\left(\mathrm{X}^{2}\right)$ and Fisher's exact test when appropriate were used for analysis of qualitative variables. 
$\mathrm{P}$ value $<0.05$ was considered statistically significant.

\section{Research ethics:}

Informal consent was obtained from all participating nurses. The questionnaire was anonymous. Before starting the research; we got approval from the hospital directors.

\section{Results}

Table (1) shows the eating patterns of study nurses for different food items, more than half of nurses eat red meat(beef or lamb) $>4$ times weekly $(61.1 \%)$, while $48.8 \%$ eat chicken/fish 2-3 times weekly with $42.7 \%$ of nurses rarely remove skin from chicken. About $44 \%$ of studied nurses eat eggs two to three times per week while $34 \%$ eat beans, and/or lentils 2-3 times per week. About $46 \%$ and $42 \%$ of studied nurses eat cheese/yogurt/milk products or vegetables 2-3 times weekly respectively. Plant Oil was the most common used type of oil/butter, as $58.8 \%$ of nurses reported using it. As seen in the table, $48.8 \%$ of nurses rarely had their breakfast and 37\% reported taken fast food 2 to 3 times /week. Overall, the majority of nurses had semihealthy diet $(89 \%), 8.8 \%$ of them had Unhealthy Diet while only $2.2 \%$ get a healthy diet.

There was a significant difference between nurses with different age group as regard dietary behaviors, as $12.2 \%$ of nurses in 31-39 age group had unhealthy diet, compared to only $6.1 \%$, and $6.8 \%$ of nurses in $\leq 30$ and $\geq 41$ year's old group nurses respectively. However, no significant difference was found between nurses with different marital status regarding dietary behaviors as $7.8 \%$,
$7.9 \%$ and $12.5 \%$ of single, married and divorced/widow nurses had unhealthy diet respectively. (Table2).

The association between dietary behavioral and body weight status revealed that $11.1 \%$ of nurses with healthy diet were obese, compared to $20 \%$, and $14.9 \%$ of nurses with unhealthy and semi healthy diet respectively; yet the difference was statistically insignificant (table3). Around $29.0 \%$ of nurses with unhealthy diet were smokers, compared to $11.5 \%$, and $11.1 \%$ of nurses with semi-healthy and unhealthy diet respectively and this difference was statistically significant. However; no significant difference observed between nurses with different dietary behaviors and physical exercise.

There was a significant difference between nurses with different duration of night shift regarding dietary behaviors, as $13.6 \%$ of nurses with $>10$ year duration in night shifts, had unhealthy diet compared to only $6.8 \%$, and $6.9 \%$ of nurses with $<5$ years and 5 10 years work duration respectively. Similarly, $4.7 \%$ of nurses working in Internal Medicine/Pediatrics, had healthy diet were compared to only $0.4 \%$, of nurses working in Surgery/Obstetrics department. The analysis revealed that there was no significant difference between nurses with different dietary behaviors regarding job satisfaction (table 4).

There was a significant difference between nurses with different dietary behaviors regarding gastrointestinal symptoms except for abdominal pain. Acidity was common among nurses with unhealthy diet (94.3\%) compared to $78.7 \%$, and $11.1 \%$ of nurses with semi healthy and unhealthy diet respectively. Similarly, regurgitation was common 
among nurses with unhealthy diet (71.4\%) compared to $60.4 \%$, and $11.1 \%$ of nurses with semi healthy and unhealthy diet respectively. Also, abdominal distension was common among nurses with unhealthy diet (71.4\%) compared to $51.7 \%$, and $11.1 \%$ of nurses with semi healthy and unhealthy diet respectively (table 5)

\section{Discussion}

Nurses often practice unhealthy behaviors, such as not engaging in regular exercise, not being involved in leisure activities, and not having healthy dietary habits, particularly owing to irregular rotating shifts and night shifts $^{18}$. Egyptian nurses are particularly vulnerable to faulty dietary behaviors due to high patient-to-nurse ratios; however, there are few studies on Egyptian hospital nurses' dietary behaviors.

Our study showed variable percentages of nurses with unhealthy eating behaviors as having fast foods, not removing poultry skin, and rarely taking breakfast but others had a healthy behavior like eating fruits and vegetables. This variability in eating habits resulted in $89 \%$ of nurses having a semi-healthy diet, $8 \%$ eating unhealthy food and $2 \%$ only with healthy diet intake. In contrary to our result, Nancy et al., reported that $66.3 \%$ of nurses had a moderately healthy diet, $16.7 \%$ had a mostly healthy diet and $17 \%$ had an unhealthy diet ${ }^{19}$.

In this study; around half of nurses rarely or once/week had taken their breakfast. No time for breakfast is one of the factors which associated with chronic distress. Moreover, nurses frequently mentioned lack of time to prepare healthy meals due to long working hours and being overtired from work. Buying fast foods was regarded as the most convenient option, and in most cases fast foods were unhealthy ${ }^{\mathbf{2 0}}$. Also, in this work more than $50 \%$ of nurses often ate fast food two and more times per week. This was similar to a Korean study where nurses with rotating night shift schedules had more unhealthy dietary behaviors, such as skipping breakfast and eating late night snacks ${ }^{21}$

Our results showed that one every five nurses reported removing chicken skin. High fat foods (rarely removing chicken skin) tend to have greater calorie levels, but less beneficial nutrients such as vitamins and minerals. This pattern leads to a greater likelihood of fat deposition to cause obesity. The final part of this cycle is that obesity is linked to the development of cardiovascular diseases, type II diabetes and osteoarthritis ${ }^{22}$.

Around $30 \%$ of nurses in this study reported rare or once/week ate vegetables and fruits while $41.5 \%$ reported 2 to 3 times per week. Eating fruits and vegetables which are considered as foods that are rich in antioxidants is essential. Antioxidants help in decreasing inflammation and subsequent oxidative stress ${ }^{23}$. Oxidative stress occurs when an overproduction of byproducts from normal cellular metabolism causes damage to components of the human body such as deoxyribonucleic acid (DNA), lipids and proteins ${ }^{24}$. This is very poor for the body and can affect metabolism and how food is utilized as a fuel.

The current work revealed that the nurses aged 31-39 had significantly higher percentage of nurses eating unhealthy diet compared to those in 
other age groups. This may be explained by the expected more social obligations in the age group (31-39) leading to having no time for preparing healthy food. No significant association was found between marital status and type of diet. In another study, nurses' age and marital status were not related to healthy $\operatorname{diet}^{19}$. Smoking status was associated with less healthy diets, this agrees with our finding where the percentage of smokers among nurses eating unhealthy diet was significantly higher than the percentage of smokers among those eating healthy and semi-healthy food ${ }^{19}$.

In the current study, the percentage of those doing no or rare exercise among nurses eating unhealthy diet was higher but without statistical significance than that of those eating semi healthy or healthy diet. This could be explained by the fact that healthy diet and proper physical activity are always interrelated. When barriers and facilitators to physical activity in the workplace were studied, time was a universal concern, and specific issues were shift work, scheduling and work conflicts ${ }^{25}$. This may explain why a high percentage of our study participants were not involved in practicing physical activity.

The etiology of obesity involves a complex interplay between genetics and environmental or lifestyle factors $\mathbf{2 6}^{\mathbf{6}}$. Eating practices associated with the global obesity epidemic include increased consumption of energy dense, but nutrient poor foods, low consumption of dairy products, fruits and vegetables, skipping breakfast and insufficient physical activity 27-30. This agrees with our findings where an association between obesity and eating behavior was detected, as $20 \%$ of nurses eating unhealthy diet were obese compared to only $14.9 \%$ and $11.1 \%$ of nurses with semi healthy and healthy diet respectively.

Regarding job satisfaction, the current study population was either dissatisfied or uncertain. No nurse experienced satisfaction with her job; this reflects that the majority are under work stress which can be cause of or a result of dissatisfaction. In a study by Alnems et al, 2005 and in another by Kamal et al., 2012; they reported a significant negative relationship between job related stress and job satisfaction ${ }^{31-32}$.

Our study found that the percentage of those working $>10$ years and eating unhealthy diet was significantly higher than that of those working less than 5 years and eating unhealthy food. This may be explained by the fact that as work duration increases, stress increases and stress is associated with unhealthy diet intake ${ }^{33}$.

Moreover, the majority of nurses eating healthy diet were working in internal medicine department/ pediatrics $(88.9 \%)$ which was significantly higher than the corresponding percentages among those eating unhealthy or semi healthy diet. This may be explained by the fact that internal medicine departments characterized by having a higher percentage of chronic stable patients compared to surgery and obstetrics departments where emergency situation is more common and patients' turnover is usually high resulting in more stress to nurses. This finding is in agreement to the results of Huda et al., where working in surgical departments was from the predictors of work related stress ${ }^{\mathbf{3 4}}$ 
In this current study there was a relationship between dietary behavioral and gastrointestinal symptoms such as acidity, regurgitation and abdominal distension. Previous studies have addressed a variety of maladies associated with shift work, including gastrointestinal (GI) symptoms ${ }^{35}$. A study showed that working in different shifts can harm the GI normal movements and cause disorders in excreting digestive enzymes and acidalkaline balance ${ }^{36}$. This may explain our findings of significant association between symptoms of acidity, regurgitation and abdominal distension with unhealthy diet intake which is a factor in the etiology of gastrointestinal disturbances.

\section{Conclusion and recommendations}

In conclusion, the majority of nurses working in rotating shift have semi healthy or unhealthy dietary behavior. Nurses working in surgery/obstetric and gynecology departments, and those with longer duration of shift work showed the higher percentage of nurses with unhealthy diet. Nurses working in night shift suffer different gastrointestinal problems which is significantly more prominent among those with unhealthy diet. Nurses having rotating shift, should be counseled on healthy dietary programs to improve their dietary behavior and nutritional status.

\section{References}

1) Burton J: WHO Healthy workplace framework and model: Background and supporting literature and practices. February 2010.
2) Quintiliani L, Sattelmair J, Sorensen G. The Workplace As A Setting For Interventions To Improve Diet And Promote Physical Activity. WHO/WEF Joint Event on Preventing Noncommunicable Diseases in the Workplace (Dalian/ China, September 2007)

3) Batt ME. Physical activity interventions in the workplace: the rationale and future direction for workplace wellness.Br J Sports Med 2009, 43 (1):47-48

4) Skaal L, Pengpid S. Obesity and health problems among South African healthcare workers: do healthcare workers take care of themselves? S Afr Fam Pract 2011, 53(6):563-7

5) World Health Organization. Global status report on non-communicable diseases

2010.(http://www.who.int/nmh/publicati ons/ncd_report2010/en/)

6) Beers TM. Flexible schedules and shift work: replacing the 9 to5 workday. Monthly Lab Rev 2000; 123 (6):33- 40

7) Swartz LB. Experiencing night shift nursing: a daylight view. University of the Western $\mathrm{C}$ ape, Faculty of Community and Health Sciences; 2006.

8) Abdalkader R, Hayajneh F. Effect of Night Shift on Nurses Working in Intensive Care Units at Jordan University Hospital. Eur J Sci Res 2008; 23:70-86.

9) De Bacquer D, Van Risseghem M, C lays E, Kittel F, De Backer G, Braeckman L. Rotating shift work and the metabolic syndrome: a prospective 
study. Int J Epidemiol 2009 June; 38(3):848-54.

10) Zhao I, Bogossian F, Song $\mathbf{S}$, Turner C. The association between shift work and unhealthy weight: a crosssectional analysis from the Nurses and Midwives' ecohort

Study. J Occup Environ Med 2011; 53(2):153-8.

11) Nizami A, Rafique I, Aslma F.Minha FA, Najam N. Occupational stress and job satisfaction among nurses at tertiary care hospital. Int J Sci Res April 2014; 3(4):733-40

12) Nasrabadi A.N, Seif H, Latifi M, N. Rasoolzadeh N, and Emami A. Night Shift Work Experiences among Iranian Nurses: A Qualitative Study. International Nursing Re- view 2009; 56(4): 498-503.

13) Wong H, Wong MC, Wong SY and Lee $\mathbf{A}$. The Association between Shift Duty and Abnormal Eating Behavior among Nurses Working in a Major Hospital: A Cross-Sectional Study. International Journal of Nursing Studies 2010;47:1021-1027.

14) Morikawa Y, Miura K, Sasaki S, Yoshita K, Yone- yama $S$, et al, "Evaluation of the Effects of Shift Work on Nutrient Intake: A Cross Sectional Study," Journal of Occupational Health 2008; (50): 270-278.

15) Antunes LC, Levandovski R, Dantas G, Caumo W, and Hidalgo MP. Obesity and Shift Work: Chronobiological Aspects. Nutrition Research Reviews 2010; (23): 155-168.

16) Lowden A, Moreno C, Holmback U, Lennernas M, and Tucker P. Eating and shift work - effects on habits, metabolism and performance. Scand J Work Health.2010; 36(2):150-162

17) Paul E. Spector. Job Satisfaction Survey,1994, Last modified December 27, 2007.

18) King KA, Vidourek R, \& Schwiebert M. Disordered eating and job stress among nurses. Journal of Nursing Management. 2009; 17(7); 861869.

19) Nancy M. Albert, Robert Butler, Jeanne Sorrell. Factors related to healthy diet and physical activity in hospital based clinical nurses. The Online Journal of Issues in Nursing 2014; 3, manuscript 5.

20) Lindokuhle PP, Catherine ED, Estelle VL, and Tracy LK. Nurses' lifestyle behaviours, health priorities and barriers to living a healthy lifestyle: a qualitative descriptive study. BMC Nursing 2014;13(1):38. DOI: 10.1186/s12912-014-0038-6

\section{1) Kihye H, Smi CK, Kyeong SK.}

Poor dietary behaviors among hospital nurses in Seoul, South Korea. Applied Nursing Research 30 (2016) 38-44

22) Centers for Disease Control and Prevention. Adult obesity facts. 2012, retrieved from www.cdc.gov/obesity/data/adult.html.

23) Benzie I.F. Evaluation of antioxidant defence mechanisms. European Journal of Nutrition 2000; 39(2): 53-61

24) Sies H, Stahl W, Sevanian A. Nutritional dietary and postprandial 
oxidative stress. Journal of Nutrition 2005; 135(5): 969-972.

25) Fletcher GM, Behrens TK, \& Domina L. Barriers and enabling factors for work-site physical activity programs: A qualitative examination. Journal of Physical Activity and Health 2008; 5(3): 418-429

26) Gee M, Mahan LK, Escott-Stump S. Weigh management. In: Mahan KL, Escott-

Stump S, editors. Krause's food, nutrition and diet therapy. 12th ed. Philadelphia:

Elsevier; 2008: 532-562.

27) Ledikwe JH, Blanck HM, Khan LK, et al. Dietary energy density is associated with energy intake and weight status in US adults. Am J Clin Nutr. 2006;83:1362-1368.

28) Lanou AJ, Barnard ND. Dairy and weight loss hypothesis: an evaluation of the

clinical trials. Nutr Rev. 2008;66(5):272-279.

29) Berkey CS, Rockett HRH, Gillman MW, Field AE, Colditz GA. Longitudinal study of skipping breakfast and weight change in adolescents. Int $\mathbf{J}$ Obes. 2003;27:12581266.

30) Kirk SFL, Penney TL, McHugh TF. Characterising the obesogenic environment: the state of the evidence with directions for future research. Obes Rev. 2009;11:109_ 117.
31) Alnems A, Aboads F, Yousef MA, Yateem NA, Abotabar N. Nurses perceived job related stress and job satisfaction in Amman privet hospitals (unpublished thesis). 2005 Jan.

32) Kamal SM, Dhsha MA, Salman KA, Abuadas F, Mohammed M. The effect of nurses perceived job related stressors on job satisfaction in Taif governmental hospitals in Taif governmental hospital in Kingdom of Saudi Arabia. J American Science 2012; 8(3):119-125

33) Heath G, Roach GD, Dorrian J, Ferguson, SA, Darwent D, \& Sargent, C. The effect of sleep restriction on snacking behavior during a week of simulated shiftwork. Accident; Analysis and Prevention 2012; 45(Suppl.): 62-67

34) Huda M. Al-Makhaita, Amr A. Sabra and Ahmed S. Hafez. Predictors of work related stress among nurses working in primary and secondary health care levels in Dammam, Eastern Saudi Arabia. J Family Community Medicine 2014; 21(2): 79-84.

35) Poissonnet CM, Veron M. Health effects of work schedules in healthcare professions. J Clin Nurs 2000; 9:13-23), (Knutson A: Health disorders of shift workers. Occupational Medicine 2003; 53:103-108.

36) Claire C, Sally L, Brenda W. Relationship of work schedules to gastrointestinal diagnoses, symptoms, and medication use in auto factory workers. Am J Indus Med 2004; 46(6):586-598. 
Table 1: The eating patterns of study nurses for different food items:

\begin{tabular}{|c|c|c|}
\hline Food Items & Frequency & Percent \\
\hline $\begin{array}{l}\text { 1-How many times/week do you eat red meat: beef or lamb? } \\
\text { Once or rare } \\
2 \text { to } 3 \text { times } \\
4+\text { times }\end{array}$ & $\begin{array}{r}23 \\
132 \\
245\end{array}$ & $\begin{array}{r}5.7 \\
33.0 \\
61.3\end{array}$ \\
\hline $\begin{array}{l}\text { 2-How many times/week do you eat Chicken/Fish? } \\
\text { Once or rare } \\
2 \text { to } 3 \text { times } \\
\text { 4+ times }\end{array}$ & $\begin{array}{r}170 \\
195 \\
35\end{array}$ & $\begin{array}{r}42.5 \\
48.8 \\
8.7\end{array}$ \\
\hline $\begin{array}{l}\text { 3- How often do you remove skin from chicken? } \\
\text { Always } \\
\text { Sometimes } \\
\text { Rare }\end{array}$ & $\begin{array}{r}85 \\
144 \\
171\end{array}$ & $\begin{array}{l}21.3 \\
36.0 \\
42.7\end{array}$ \\
\hline $\begin{array}{l}\text { 4-How often do you eat eggs/week? } \\
\text { Once or rare } \\
2 \text { to } 3 \text { times } \\
4+\text { times }\end{array}$ & $\begin{array}{r}162 \\
174 \\
64\end{array}$ & $\begin{array}{l}40.5 \\
43.5 \\
16.0\end{array}$ \\
\hline $\begin{array}{l}\text { 5- How often do you eat beans, and/or lentils/week? } \\
\text { Once or rare } \\
2 \text { to } 3 \text { times } \\
\text { 4+ times }\end{array}$ & $\begin{array}{r}53 \\
136 \\
211 \\
\end{array}$ & $\begin{array}{l}13.2 \\
34.0 \\
52.8\end{array}$ \\
\hline $\begin{array}{l}\text { 6- How often do you eat cheese/yogurt/milk products/week? } \\
\text { Once or rare } \\
2 \text { to } 3 \text { times } \\
4+\text { times }\end{array}$ & $\begin{array}{r}167 \\
185 \\
48\end{array}$ & $\begin{array}{l}41.8 \\
46.2 \\
12.0\end{array}$ \\
\hline $\begin{array}{l}\text { 7- How often do you eat vegetables (at least one plate) /fruits at } \\
\text { least one piece per week? } \\
\text { Once or rare } \\
2 \text { to } 3 \text { times } \\
\text { 4+ times }\end{array}$ & $\begin{array}{l}113 \\
166 \\
121\end{array}$ & $\begin{array}{l}28.2 \\
41.5 \\
30.3\end{array}$ \\
\hline $\begin{array}{l}\text { 8- What is the usual type of Oil/Butter used in cooking? } \\
\text { Artificial Margarine } \\
\text { Plant Oil } \\
\text { Natural Butter }\end{array}$ & $\begin{array}{r}142 \\
235 \\
23\end{array}$ & $\begin{array}{r}35.5 \\
58.8 \\
5.7\end{array}$ \\
\hline $\begin{array}{l}\text { 9- How often do you take breakfast/week? } \\
\text { Once or rare } \\
2 \text { to } 3 \text { times } \\
\text { 4+ times }\end{array}$ & $\begin{array}{r}195 \\
177 \\
28 \\
\end{array}$ & $\begin{array}{r}48.8 \\
44.2 \\
7.0 \\
\end{array}$ \\
\hline $\begin{array}{l}\text { 10- How often do you eat fast-food/week? } \\
\text { Once or rare } \\
2 \text { to } 3 \text { times } \\
\text { 4+ times }\end{array}$ & $\begin{array}{r}173 \\
148 \\
79\end{array}$ & $\begin{array}{l}43.3 \\
37.0 \\
19.7\end{array}$ \\
\hline $\begin{array}{l}\text { Unhealthy Diet } \\
\text { Semi Healthy Diet } \\
\text { Healthy Diet }\end{array}$ & $\begin{array}{r}35 \\
356 \\
9\end{array}$ & $\begin{array}{r}8.8 \\
89.0 \\
2.2\end{array}$ \\
\hline
\end{tabular}


Table 2: Relationship between dietary behavior and age and marital status of study nurses

\begin{tabular}{|c|c|c|c|c|}
\hline Characteristic & $\begin{array}{l}\text { Unhealthy } \\
(\mathrm{N}=35) \\
\text { Frequency } \\
(\%)\end{array}$ & $\begin{array}{l}\text { Semi-Healthy } \\
(\mathrm{N}=356) \\
\text { Frequency }(\%)\end{array}$ & $\begin{array}{l}\text { Healthy } \\
(\mathrm{N}=9) \\
\text { Frequency }(\%)\end{array}$ & $\mathrm{P}$ value \\
\hline $\begin{array}{c}\text { Age groups } \\
\leq 30 \\
31-39 \\
\geq 40\end{array}$ & $\begin{array}{l}10(6.1)^{*} \\
20(12.2) \\
5(6.8)\end{array}$ & $\begin{array}{l}152(93.3) \\
136(82.9) \\
68(93.2)\end{array}$ & $\begin{array}{l}1(0.6) \\
8(4.9) \\
0(0.0)\end{array}$ & $0.013^{\#}$ \\
\hline $\begin{array}{l}\text { Marital Status } \\
\text { Married } \\
\text { Divorced/Widow } \\
\text { Single }\end{array}$ & $\begin{array}{l}15(7.8)^{*} \\
10(7.9) \\
10(12.5)\end{array}$ & $\begin{array}{l}171(88.1) \\
116(92.1) \\
69(86.3)\end{array}$ & $\begin{array}{l}8(4.1) \\
0(0.0) \\
1(1.2)\end{array}$ & $0.086 \#$ \\
\hline
\end{tabular}

\# using Fisher's Exact Test

*row $\%$

Table 3: Relationship between dietary behavior and life style factors of study nurses

\begin{tabular}{|c|c|c|c|c|}
\hline Characteristic & $\begin{array}{l}\text { Unhealthy } \\
(\mathrm{N}=35) \\
\text { Frequency }(\%) \\
\end{array}$ & $\begin{array}{l}\text { Semi Healthy } \\
(\mathrm{N}=356) \\
\text { Frequency }(\%)\end{array}$ & $\begin{array}{l}\text { Healthy } \\
(\mathrm{N}=9) \\
\text { Frequency }(\%) \\
\end{array}$ & $P$ value \\
\hline $\begin{array}{l}\text { Body Weight status } \\
\text { Normal } \\
\text { Overweight } \\
\text { Obese }\end{array}$ & $\begin{array}{c}14(40.0)^{*} \\
14(40.0) \\
7(20.0)\end{array}$ & $\begin{array}{r}142(39.9) \\
161(45.2) \\
53(14.9)\end{array}$ & $\begin{array}{l}7(78.8) \\
1(11.1) \\
1(11.1)\end{array}$ & $0.184 \#$ \\
\hline $\begin{array}{l}\text { Tobacco smoking } \\
\text { Smokers } \\
\text { Non smokers }\end{array}$ & $\begin{array}{l}10(28.6)^{*} \\
25(71.4)\end{array}$ & $\begin{array}{r}41(11.5) \\
315(88.5)\end{array}$ & $\begin{array}{l}1(11.1) \\
8(88.9)\end{array}$ & $0.025 \#$ \\
\hline $\begin{array}{c}\text { Physical exercise/week } \\
\text { No / rare } \\
1 \text { to } 3 \text { times } \\
\geq 4 \text { times }\end{array}$ & $\begin{aligned} 22 & (62.9)^{*} \\
9 & (25.7) \\
4 & (11.4)\end{aligned}$ & $\begin{array}{r}205(57.6) \\
95(26.7) \\
56(15.7) \\
\end{array}$ & $\begin{array}{l}5(55.6) \\
2(22.2) \\
2(22.2)\end{array}$ & $0.925 \#$ \\
\hline
\end{tabular}

\# using Fisher's Exact Test

*column \% 
Table 4: Relationship between dietary behavior and working characteristics

\begin{tabular}{|c|c|c|c|c|}
\hline Characteristic & $\begin{array}{l}\text { Unhealthy } \\
(\mathrm{N}=35) \\
\text { Frequency }(\%)\end{array}$ & $\begin{array}{l}\text { Semi Healthy } \\
\quad(\mathrm{N}=356) \\
\text { Frequency }(\%)\end{array}$ & $\begin{array}{c}\text { Healthy } \\
(\mathrm{N}=9) \\
\text { Frequency }(\%)\end{array}$ & $\mathrm{P}$ value \\
\hline $\begin{array}{c}\text { Duration of night shift } \\
<5 \text { years } \\
5 \text { to } 10 \text { years } \\
>10 \text { years }\end{array}$ & $\begin{array}{l}10(6.8)^{*} \\
10(6.9) \\
15(13.6)\end{array}$ & $\begin{array}{r}136(93.1) \\
126(87.5) \\
94(85.5)\end{array}$ & $\begin{array}{l}0(0.0) \\
8(5.6) \\
1(0.9)\end{array}$ & $0.004^{\#}$ \\
\hline $\begin{array}{l}\text { Department of work } \\
\text { Surgery/Obstetrics } \\
\text { Internal Medicine/Pediatrics }\end{array}$ & $\begin{array}{l}20(8.7) * \\
15(8.8)\end{array}$ & $\begin{array}{l}209(90.9) \\
147(86.5) \\
\end{array}$ & $\begin{array}{l}1(0.4) \\
8(4.7) \\
\end{array}$ & $0.017^{@}$ \\
\hline $\begin{array}{c}\text { Job Satisfaction } \\
\text { Dissatisfied } \\
\text { Uncertain }\end{array}$ & $\frac{17(9.8)}{18(8.0)}$ * & $\begin{array}{l}\frac{152(87.3)}{204(90.3)} \\
\underline{4}\end{array}$ & $\begin{array}{l}5(2.9) \\
4(1.8)\end{array}$ & $0.635^{@}$ \\
\hline
\end{tabular}

\# using Fisher's Exact Test

@ using Chi Square Test

*row $\%$

\section{Table 5: Relationship between dietary behavior and some gastro- intestinal problems}

\begin{tabular}{|c|c|c|c|c|}
\hline Characteristic & $\begin{array}{l}\text { Unhealthy } \\
(\mathrm{N}=35) \\
\text { Frequency }(\%) \\
\end{array}$ & $\begin{array}{l}\text { Semi Healthy } \\
(\mathrm{N}=356) \\
\text { Frequency }(\%)\end{array}$ & $\begin{array}{l}\text { Healthy } \\
(\mathrm{N}=9) \\
\text { Frequency }(\%) \\
\end{array}$ & P value \\
\hline $\begin{array}{l}\text { Acidity } \\
\text { Always/Sometimes } \\
\text { No/Rare }\end{array}$ & $\begin{array}{c}33(94.3)^{*} \\
2(5.7)\end{array}$ & $\begin{array}{r}280(78.7) \\
76(21.3)\end{array}$ & $\begin{array}{l}1(11.1) \\
8(88.9)\end{array}$ & $<0.001 \#$ \\
\hline $\begin{array}{l}\text { Regurgitation } \\
\text { Always/Sometimes } \\
\text { No/Rare }\end{array}$ & $\begin{array}{l}25(71.4)^{*} \\
10(28.6)\end{array}$ & $\begin{array}{l}215(60.4) \\
141(39.4)\end{array}$ & $\begin{array}{l}1(11.1) \\
8(88.9)\end{array}$ & 0.003@ \\
\hline $\begin{array}{l}\text { Abdominal Distension } \\
\text { Always/Sometimes } \\
\text { No/Rare }\end{array}$ & $\begin{array}{l}25(71.4)^{*} \\
10(28.6)\end{array}$ & $\begin{array}{l}184(51.7) \\
172(48.3)\end{array}$ & $\begin{array}{l}1(11.1) \\
8(88.9)\end{array}$ & 0.003\# \\
\hline $\begin{array}{l}\text { Abdominal pain } \\
\text { Always/Sometimes } \\
\text { No/Rare }\end{array}$ & $\begin{array}{r}2(5.7)^{*} \\
33(94.3)\end{array}$ & $\begin{array}{r}68(19.1) \\
288(80.9)\end{array}$ & $\begin{array}{l}1(11.1) \\
8(88.9)\end{array}$ & $0.119 \#$ \\
\hline
\end{tabular}

\# using Fisher's Exact Test

@ using Chi Square Test

*column \% 